\title{
Thromboprophylaxis with Rivaroxaban in Acutely III Medical Patients with Renal Impairment: Insights from the MAGELLAN and MARINER Trials
}

\author{
Jeffrey I. Weitz ${ }^{1}$ Gary E. Raskob ${ }^{2}$ Alex C. Spyropoulos ${ }^{3,4,5}$ Theodore E. Spiro ${ }^{6}$ Yoriko De Sanctis ${ }^{7}$ \\ jianfeng $\mathrm{Xu}^{8}$ Wentao $\mathrm{Lu}^{8}$ Eunyoung Suh ${ }^{8}$ Domenick Argenti ${ }^{8}$ Haitao Yang ${ }^{8}$ John Albanese ${ }^{8}$ \\ Concetta Lipardi ${ }^{8}$ Elliot S. Barnathan ${ }^{8}$
}

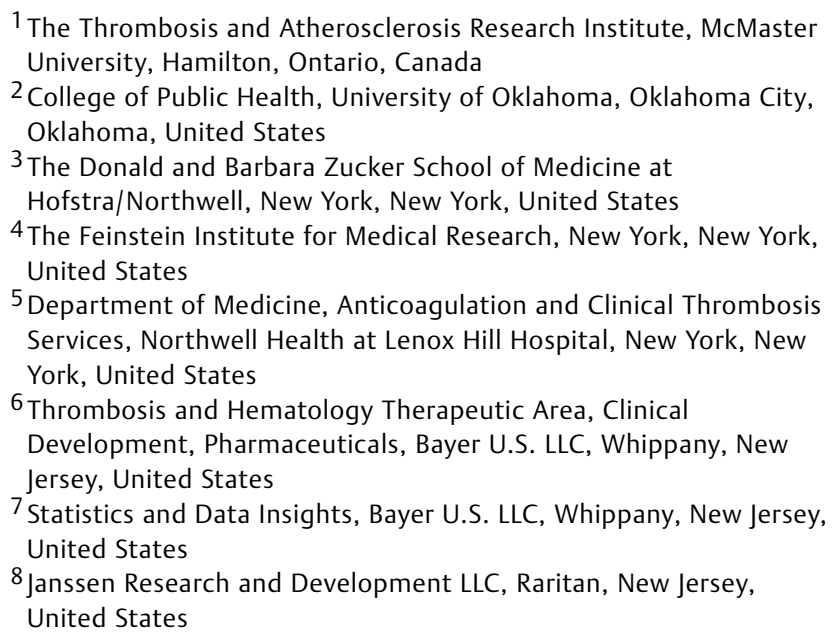

Address for correspondence Jeffrey I. Weitz, MD, FRCP(C), FACP, Thrombosis and Atherosclerosis Research Institute, 237 Barton Street East, Hamilton, ON L8L 2X2, Canada (e-mail: weitzj@taari.ca).

Thromb Haemost 2020;120:515-524.

\begin{abstract}
Keywords

- anticoagulants

- medically ill

- renal impairment

- venous thromboembolism

- rivaroxaban

Patients with renal impairment are at higher risk of thrombosis and bleeding than those with normal renal function. The optimal rivaroxaban dose for thromboprophylaxis in acutely ill medical patients with renal impairment is unknown. MARINER and MAGELLAN were multicenter, randomized clinical trials of rivaroxaban in acutely ill medical patients. Efficacy and safety outcomes in patients with renal impairment in MARINER (7.5 mg once daily) were compared with those in patients with normal renal function in MARINER (10 mg once daily) and in a subpopulation of MAGELLAN that excluded patients at high risk for bleeding at baseline (10 mg once daily). Compared with enoxaparin/placebo in the MAGELLAN subpopulation, the relative risk (RR) of symptomatic venous thromboembolism (VTE) and VTE-related death with rivaroxaban $10 \mathrm{mg}$ in patients with renal impairment $(\mathrm{RR}=0.62 ; 95 \%$ confidence interval $[\mathrm{Cl}]$ $0.27-1.44$ ) was similar to that in those with normal renal function $(R R=0.78 ; 95 \% \mathrm{Cl}$ $0.44-1.40$ ), while in MARINER, the $7.5 \mathrm{mg}$ dose did not reduce the risk in patients with renal impairment (hazard ratio $=1.00 ; 95 \% \mathrm{Cl} 0.52-1.92$ ). Major bleeding with rivaroxaban $10 \mathrm{mg}$ once daily was higher in patients with renal impairment than in those with normal renal function in MAGELLAN $(1.54 \%$ vs. $0.98 \%)$ and in the MAGELLAN subpopulation $(0.94 \%$ vs. $0.61 \%)$. At a dose of $10 \mathrm{mg}$ once daily,
\end{abstract}

received

October 4, 2019

accepted after revision December 4, 2019
DOI https://doi.org/ $10.1055 / \mathrm{s}-0039-1701009$ ISSN 0340-6245.
(C) 2020 Georg Thieme Verlag KG Stuttgart · New York
License terms

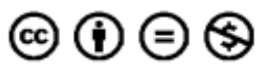


rivaroxaban is effective for thromboprophylaxis in acutely ill medical patients with impaired or normal renal function. The safety of this regimen is enhanced without loss of efficacy by excluding patients at high risk for bleeding, but not by using a reduceddose strategy.

Trial Registration ClinicalTrials.gov identifiers: NCT00571649 for the MAGELLAN trial, NCT02111564 for the MARINER trial.

\section{Introduction}

Acutely ill medical patients are at risk of venous thromboembolism (VTE), which includes deep vein thrombosis (DVT) and pulmonary embolism (PE). At least $65 \%$ of fatal PE occur in medical patients, ${ }^{1}$ who remain at risk for VTE for at least 3 months after discharge from hospital. ${ }^{2,3}$ Guidelines recommend in-hospital thromboprophylaxis for medical patients with heart failure or severe respiratory disease, or for those confined to bed with additional risk factors such as infection, inflammatory disease, stroke, or prior VTE. ${ }^{4,5}$ Balancing the benefits and risks of anticoagulant thromboprophylaxis is difficult in patients with renal impairment because they have hemostatic abnormalities that increase their risk of thrombosis and bleeding. ${ }^{6}$ Furthermore, anticoagulants such as enoxaparin and rivaroxaban are cleared via the kidneys, which may lead to drug accumulation and bleeding in patients with impaired renal function. ${ }^{7}$ Therefore, there remains a need for strategies that render anticoagulant thromboprophylaxis in acutely ill medical patients as effective and safe in patients with renal impairment as it is in those with normal renal function.

To identify the optimal dose of rivaroxaban for thromboprophylaxis in acutely ill medical patients with impaired renal function, we used data from the MAGELLAN and MARINER trials. $^{8,9}$ MAGELLAN compared rivaroxaban with enoxaparin during the in-hospital phase and with placebo for extended thromboprophylaxis, whereas MARINER compared rivaroxaban with placebo only in the outpatient phase. Rivaroxaban was administered at a dose of $10 \mathrm{mg}$ once daily in both studies, but in the MARINER trial, the dose was reduced to $7.5 \mathrm{mg}$ once daily in patients with renal impairment (creatinine clearance $30-49 \mathrm{~mL} / \mathrm{min}$ ). Incidences of VTE and bleeding in patients with renal impairment were compared with those in patients with normal renal function in all patients and in a subpopulation of those in the MAGELLAN trial, which excluded patients with risk factors for major bleeding using the exclusion criteria employed in the MARINER trial.

\section{Methods}

\section{Study Population}

We included patients enrolled in the previously reported MAGELLAN and MARINER trials. ${ }^{8-11}$ Patients had to have a creatinine clearance of $30 \mathrm{~mL} / \mathrm{min}$ or higher to be enrolled. The MAGELLAN trial (NCT00571649) was a multicenter, randomized, double-blind, parallel-group efficacy and safety study comparing oral rivaroxaban (10 mg once daily) administered for $35 \pm 4$ days with subcutaneous enoxaparin ( $40 \mathrm{mg}$ once daily) administered for $10 \pm 4$ days followed by placebo for thromboprophylaxis in hospitalized acutely ill medical patients. Eligible patients included those at least 40 years of age who were hospitalized for an acute medical illness (i.e., heart failure, active cancer, acute ischemic stroke, acute infectious and inflammatory disease, and acute respiratory insufficiency) and were at risk for VTE because of immobility, or had additional risk factors such as age $\geq 75$ years, history of cancer, history of VTE, history of heart failure, thrombophilia, acute infectious disease contributing to the hospitalization, and body mass index $\geq 35 \mathrm{~kg} / \mathrm{m}^{2}$. The MARINER trial (NCT02111564) was a multicenter, randomized, double-blind, parallel-group efficacy and safety study that compared rivaroxaban with placebo for out-of-hospital thromboprophylaxis in acutely ill medical patients discharged from hospital. Patients were stratified at baseline by renal function; subjects with normal renal function (i.e., creatinine clearance $\geq 50 \mathrm{~mL} / \mathrm{min}$ ) received rivaroxaban $10 \mathrm{mg}$ once daily (or placebo), while those with renal impairment (i.e., creatinine clearance $30-49 \mathrm{~mL} / \mathrm{min}$ ) received rivaroxaban $7.5 \mathrm{mg}$ once daily (or placebo). Treatments were given for 45 days. In all patients, creatinine clearance was measured before randomization using the Cockcroft-Gault formula. ${ }^{12}$ Eligible patients were those at least 40 years of age, hospitalized for an acute medical illness (i.e., heart failure, acute ischemic stroke, acute infectious and inflammatory disease, and acute respiratory insufficiency), and at high risk of VTE based on a modified International Medical Prevention Registry on VTE (IMPROVE) risk assessment model score of 4 or more (or a score of 2 or 3 with a Ddimer level $>2$ times the upper limit of normal). The MARINER trial excluded patients with risk factors for major bleeding including five key exclusionary criteria: active cancer at randomization, medical history of bronchiectasis or pulmonary cavitation, use of dual antiplatelet therapy at baseline, active gastroduodenal ulcer, or any bleeding in the 3 months prior to randomization. The previously described subpopulation of MAGELLAN excluded approximately $20 \%$ of patients with the risk factors for major bleeding used to exclude patients in MARINER. ${ }^{13}$ Demographic data and clinical characteristics across the three populations were reported by baseline creatinine clearance.

\section{Efficacy and Safety Outcomes}

The incidences of VTE and bleeding in patients with and without renal impairment were compared in MAGELLAN, in the MAGELLAN subpopulation, and in MARINER. The primary efficacy outcome in the MAGELLAN trial was the composite of asymptomatic proximal DVT detected by mandatory bilateral 
lower extremity venous ultrasonography, symptomatic VTE, and VTE-related death. All suspected events were adjudicated by committees blinded to treatment assignment. In the MARINER trial, the primary efficacy outcome was the composite of symptomatic VTE and VTE-related death as adjudicated by a committee blinded to treatment assignment. The incidence of asymptomatic proximal DVT was not assessed in MARINER. The primary safety outcome of MAGELLAN was treatmentemergent clinically relevant bleeding defined as the composite of major and clinically relevant nonmajor bleeding, while the primary safety outcome of MARINER was major bleeding. All suspected bleeding events were adjudicated and classified using the International Society on Thrombosis and Haemostasis criteria. ${ }^{14}$

\section{Pharmacokinetics}

In the MARINER study, two samples for pharmacokinetic (PK) analysis were obtained on day 7 (predose and $1-4$ hours postdose). Another two samples were obtained on day 21 (3-7 and 7-12 hours postdose). In the MAGELLAN study, blood samples for PK and coagulation evaluation were obtained on day 1 (predose and 1, 2, 3, 4, 6, 9, and 12 hours postdose) and on day $10 \pm 4$ days (predose and $1,2,3,4,6,9$, and 12 hours postdose). The plasma rivaroxaban concentrations were determined using a validated liquid chromatography-tandem mass spectrometry method. Only concentrations above the lower limit of quantification $(0.5 \mathrm{ng} / \mathrm{mL})$ were included in the subsequent population PK analysis. The population PK model for rivaroxaban used in this analysis was developed previously ${ }^{15}$ in patients with acute symptomatic DVT from the phase IIb clinical studies and a study in total hip replacement. ${ }^{16,17}$ The new PK parameter estimates, such as steady-state area under the concentration curve (AUCss) and steady-state maximal concentration, for the current MARINER and MAGELLAN population were used to generate the empirical Bayesian (individual) predictions for all observations. Based upon individual plasma rivaroxaban concentration versus time data in patients taking the 7.5 or $10 \mathrm{mg}$ dose of rivaroxaban, the PKs and rivaroxaban exposure were derived using population PK modeling and were reported based on the baseline creatinine clearance.

\section{Statistical Analysis}

Demographic and clinical characteristics were reported according to treatment group and baseline creatinine clearance for the safety population, which included all randomized patients who received at least one dose of study medication. In the MAGELLAN trial, the efficacy analysis for total (asymptomatic and symptomatic) VTE and VTE-related death focused on the modified intent-to-treat population, which included all randomized patients who received at least one dose of study medication and had adequate ultrasonographic assessment of the proximal deep veins of the legs or symptomatic nonfatal or fatal VTE. Efficacy analyses for symptomatic VTE and VTErelated death were conducted in the safety population. In the MARINER trial, efficacy analysis for symptomatic VTE and VTErelated death focused on the intention-to-treat population, which included all randomized patients who provided valid informed consent.
Efficacy and safety analyses were performed using the study definitions, data rules, and derivations outlined in the MAGELLAN and MARINER Statistical Analysis Plans. Briefly, the relative risks (RRs) and their corresponding 95\% confidence interval $(\mathrm{CI})$ were calculated using the Mantel-Haenszel method ${ }^{18}$ for MAGELLAN and the hazard ratios and their corresponding 95\% Cls were calculated using the Cox proportional hazards model $^{19}$ for MARINER.

\section{Results}

\section{Demographics and Clinical Characteristics}

MAGELLAN randomized 8,101 patients from 562 sites in 52 countries. ${ }^{8}$ The MAGELLAN safety population included 7,998 patients. With the retrospective use of five key bleeding risk factors, 1,551 patients were excluded from MAGELLAN and the remaining approximately $80 \%$ of patients formed the subpopulation of MAGELLAN. MARINER randomized 12,024 patients from 671 sites in 36 countries $^{9}$ and the MARINER safety population included 11,962 patients.

Demographics and other baseline characteristics among the three populations ( - Table 1 ) were balanced between treatment groups and generally similar across the three populations except for older age in patients with renal impairment versus those with normal renal function (mean ages were approximately 78 and 67 years, respectively). The reasons for hospitalization were similar except for heart failure which was more common in those with renal impairment (range 47-55\%) than in those with normal renal function (range $28-37 \%$ ). Heart failure and hypertension were the most common medical disorders overall.

\section{Efficacy}

In the overall MAGELLAN population, the incidence of the primary efficacy endpoint (asymptomatic proximal DVT, symptomatic VTE, and VTE-related mortality) at day 35 was lower in the rivaroxaban group than in the enoxaparin/placebo group both in patients with impaired renal function $(7.18 \%$ vs. $9.48 \%$, respectively) and with normal renal function (3.73\% vs. 4.64\%, respectively) (- Fig. 1A). Compared with enoxaparin/ placebo, the RR with rivaroxaban in patients with impaired renal function $(\mathrm{RR}=0.77 ; 95 \% \mathrm{CI} 0.52-1.14)$ was similar to that in patients with normal renal function $(\mathrm{RR}=0.80$; $95 \% \mathrm{Cl} 0.61$ $1.06)$ in the MAGELLAN population and the MAGELLAN subpopulation ( - Fig 1 A).

In patients with renal impairment, the incidences of symptomatic VTE and VTE-related death with rivaroxaban and enoxaparin/placebo were 1.54 and $2.49 \%$, respectively, in MAGELLAN and 1.41 and $2.27 \%$, respectively, in the MAGELLAN subpopulation. In those with normal renal function, the incidences of symptomatic VTE and VTE-related death with rivaroxaban and enoxaparin/placebo were 0.92 and $1.11 \%$, respectively, in MAGELLAN and 0.81 and $1.06 \%$, respectively, in the MAGELLAN subpopulation (-Fig. 1B).

By contrast, the incidences of the composite of symptomatic VTE and VTE-related death at 45 days in patients with renal impairment were $1.64 \%$ with both rivaroxaban $(7.5 \mathrm{mg}$ once daily) and placebo in the MARINER study ( - Fig 1 B, left 
Table 1 Demographics and clinical characteristics by renal function

\begin{tabular}{|c|c|c|c|c|c|c|}
\hline \multicolumn{7}{|l|}{$\mathrm{CrCl} 30 \leq 50 \mathrm{~mL} / \mathrm{min}$} \\
\hline & \multicolumn{2}{|l|}{ MAGELLAN } & \multicolumn{2}{|c|}{ MAGELLAN subpopulation } & \multicolumn{2}{|l|}{ MARINER } \\
\hline & $\begin{array}{l}\text { Rivaroxaban } \\
10 \mathrm{mg} Q \mathrm{QD} \\
N=780 \\
n(\%)\end{array}$ & $\begin{array}{l}\text { Enoxaparin/ } \\
\text { placebo } \\
N=804 \\
n(\%)\end{array}$ & $\begin{array}{l}\text { Rivaroxaban } \\
10 \text { mg QD } \\
N=637 \\
n(\%)\end{array}$ & $\begin{array}{l}\text { Enoxaparin/ } \\
\text { placebo } \\
N=662 \\
n(\%)\end{array}$ & $\begin{array}{l}\text { Rivaroxaban } \\
7.5 \mathrm{mg} Q D \\
N=1,092 \\
n(\%)\end{array}$ & $\begin{array}{l}\text { Placebo } \\
N=1,091 \\
n(\%)\end{array}$ \\
\hline Age, mean $\pm S D, y$ & $78.6 \pm 8.0$ & $78.2 \pm 8.5$ & $78.8 \pm 7.9$ & $78.5 \pm 8.3$ & $78.1 \pm 7.6$ & $78.6 \pm 7.9$ \\
\hline$<65 y$ & $45(5.8)$ & $65(8.1)$ & $31(4.9)$ & $49(7.4)$ & $67(6.1)$ & $62(5.7)$ \\
\hline 65 to $<75 y$ & $151(19.4)$ & $141(17.5)$ & $119(18.7)$ & $108(16.3)$ & $208(19.1)$ & $206(18.9)$ \\
\hline$\geq 75 y$ & $584(74.9)$ & $598(74.4)$ & $487(76.5)$ & $505(76.3)$ & $817(74.8)$ & $823(75.4)$ \\
\hline Sex, male & $366(46.9)$ & $344(42.8)$ & $285(44.7)$ & $275(41.5)$ & $411(37.6)$ & $417(38.2)$ \\
\hline \multicolumn{7}{|l|}{ Reason of hospitalization } \\
\hline Heart failure & $367(47.1)$ & $372(46.3)$ & $308(48.4)$ & $320(48.3)$ & $598(54.8)$ & $577(52.9)$ \\
\hline Acute ischemic stroke & $97(12.4)$ & $102(12.7)$ & $83(13.0)$ & $92(13.9)$ & $99(9.1)$ & $94(8.6)$ \\
\hline $\begin{array}{l}\text { Acute infectious and } \\
\text { inflammatory diseases }\end{array}$ & $350(44.9)$ & $350(43.5)$ & $298(46.8)$ & $292(44.1)$ & NA & NA \\
\hline Acute infectious disease & $330(42.3)$ & $335(41.7)$ & $285(44.7)$ & $279(42.1)$ & $166(15.2)$ & $175(16.0)$ \\
\hline $\begin{array}{l}\text { Acute inflammatory } \\
\text { rheumatic disease }\end{array}$ & $33(4.2)$ & $23(2.9)$ & $26(4.1)$ & $21(3.2)$ & $11(1.0)$ & $8(0.7)$ \\
\hline $\begin{array}{l}\text { Acute respiratory } \\
\text { insufficiency }\end{array}$ & $214(27.4)$ & $229(28.5)$ & $179(28.1)$ & $192(29.0)$ & 217 (19.9) & $237(21.7)$ \\
\hline \multicolumn{7}{|l|}{ Comorbidities } \\
\hline Atrial fibrillation & $184(23.6)$ & $157(19.5)$ & $151(23.7)$ & $140(21.2)$ & $57(5.2)$ & $65(6.0)$ \\
\hline COPD & $251(32.1)$ & $254(31.6)$ & $208(32.7)$ & $212(32.0)$ & $317(29.0)$ & $339(31.1)$ \\
\hline Coronary artery disease & $193(24.7)$ & $187(23.3)$ & $156(24.5)$ & $141(21.3)$ & $210(19.2)$ & $211(19.3)$ \\
\hline Diabetes & $254(32.6)$ & $234(29.1)$ & $213(33.4)$ & $186(28.1)$ & $29(27.0)$ & $306(28.1)$ \\
\hline Heart failure & $410(52.6)$ & $408(50.8)$ & $346(54.3)$ & $354(53.5)$ & $677(62.0)$ & $650(59.6)$ \\
\hline Hypertension & $604(77.4)$ & $627(78.0)$ & $500(78.5)$ & $521(78.7)$ & $887(81.2)$ & $882(80.8)$ \\
\hline Kidney dysfunction & $276(35.4)$ & $266(33.1)$ & $223(35.0)$ & $210(31.7)$ & $125(11.5)$ & $121(11.1)$ \\
\hline Myocardial infarction & 249 (31.9) & $242(30.1)$ & $192(30.1)$ & $197(29.8)$ & $347(31.8)$ & $357(32.7)$ \\
\hline D-dimer $>2 \times$ ULN & $441(56.5)$ & $469(58.3)$ & $357(56.0)$ & $386(58.3)$ & 847 (77.6) & $858(78.6)$ \\
\hline History of cancer & $117(15.0)$ & $119(14.8)$ & $71(11.1)$ & $70(10.6)$ & $96(8.8)$ & $101(9.3)$ \\
\hline History of VTE & $39(5.0)$ & $42(5.2)$ & $33(5.2)$ & $42(6.3)$ & $100(9.2)$ & $86(7.9)$ \\
\hline \multicolumn{7}{|l|}{$\mathrm{CrCl} \geq 50 \mathrm{~mL} / \mathrm{min}$} \\
\hline & \multicolumn{2}{|l|}{ MAGELLAN } & \multicolumn{2}{|c|}{ MAGELLAN subpopulation } & \multicolumn{2}{|l|}{ MARINER } \\
\hline & $\begin{array}{l}\text { Rivaroxaban } \\
10 \mathrm{mg} \text { QD } \\
N=3,058 \\
n(\%)\end{array}$ & $\begin{array}{l}\text { Enoxaparin/ } \\
\text { placebo } \\
N=3,058 \\
n(\%)\end{array}$ & $\begin{array}{l}\text { Rivaroxaban } \\
10 \text { mg QD } \\
N=2,456 \\
n(\%)\end{array}$ & $\begin{array}{l}\text { Enoxaparin/ } \\
\text { placebo } \\
N=2,462 \\
n(\%)\end{array}$ & $\begin{array}{l}\text { Rivaroxaban } \\
10 \text { mg QD } \\
N=4,890 \\
n(\%)\end{array}$ & $\begin{array}{l}\text { Placebo } \\
N=4,889 \\
n(\%)\end{array}$ \\
\hline Age, mean $\pm S D, y$ & $66.5 \pm 11.3$ & $66.6 \pm 11.2$ & $66.8 \pm 11.4$ & $66.9 \pm 11.1$ & $67.8 \pm 9.6$ & $67.7 \pm 9.6$ \\
\hline$<65 y$ & $1,250(40.88)$ & $1,274(41.66)$ & $980(39.90)$ & $998(40.5)$ & $1,736(35.5)$ & $1,776(36.3)$ \\
\hline 65 to $<75 y$ & $965(31.56)$ & $921(30.12)$ & $766(31.19)$ & $740(30.1)$ & $1,826(37.3)$ & $1,811(37.0)$ \\
\hline$\geq 75 y$ & $843(27.57)$ & $863(28.22)$ & $710(28.91)$ & $724(29.4)$ & $1,328(27.2)$ & $1,302(26.6)$ \\
\hline Sex, male & $1,788(58.5)$ & $1,700(55.6)$ & $1,404(57.2)$ & $1,345(54.6)$ & $2,705(55.3)$ & $2,725(55.7)$ \\
\hline \multicolumn{7}{|l|}{ Reason of hospitalization } \\
\hline Heart failure & $862(28.2)$ & $881(28.8)$ & $745(30.3)$ & $771(31.3)$ & $1,834(37.5)$ & $1,812(37.1)$ \\
\hline Acute ischemic stroke & $574(18.8)$ & $574(18.8)$ & 485 (19.7) & $480(19.5)$ & $759(15.5)$ & $769(15.7)$ \\
\hline
\end{tabular}


Table 1 (Continued)

\begin{tabular}{|l|l|l|l|l|l|l|}
\hline $\begin{array}{l}\text { Acute infectious and } \\
\text { inflammatory diseases }\end{array}$ & $1,473(48.2)$ & $1,451(47.4)$ & $1,266(51.5)$ & $1,249(50.7)$ & NA & NA \\
\hline Acute infectious disease & $1,416(46.3)$ & $1,394(45.6)$ & $1,212(49.3)$ & $1,203(48.9)$ & $875(17.9)$ & $857(17.5)$ \\
\hline $\begin{array}{l}\text { Acute inflammatory } \\
\text { rheumatic disease }\end{array}$ & $115(3.8)$ & $121(4.0)$ & $104(4.2)$ & $102(4.1)$ & $74(1.5)$ & $82(1.7)$ \\
\hline $\begin{array}{l}\text { Acute respiratory } \\
\text { insufficiency }\end{array}$ & $817(26.7)$ & $880(28.8)$ & $693(28.2)$ & $725(29.4)$ & $1,346(27.5)$ & $1,369(28)$ \\
\hline Comorbidities & \multicolumn{7}{|l|}{} \\
\hline Atrial fibrillation & $361(11.8)$ & $326(10.7)$ & $309(12.6)$ & $283(11.5)$ & $146(3.0)$ & $147(3.0)$ \\
\hline COPD & $952(31.1)$ & $937(30.6)$ & $787(32.0)$ & $777(31.6)$ & $1,687(34.5)$ & $1,741(35.6)$ \\
\hline Coronary artery disease & $506(16.6)$ & $531(17.4)$ & $400(16.3)$ & $418(17.0)$ & $745(15.2)$ & $742(15.2)$ \\
\hline Diabetes & $976(31.9)$ & $933(30.5)$ & $792(32.3)$ & $772(31.4)$ & $1,447(29.6)$ & $1,368(28.0)$ \\
\hline Heart failure & $999(32.7)$ & $1,028(33.6)$ & $861(35.1)$ & $892(36.2)$ & $2,187(44.7)$ & $2,182(44.6)$ \\
\hline Hypertension & $2,050(67.0)$ & $2,027(66.3)$ & $1,711(69.7)$ & $1,685(68.4)$ & $3,825(78.2)$ & $3,856(78.9)$ \\
\hline Kidney dysfunction & $384(12.6)$ & $374(12.2)$ & $293(11.9)$ & $305(12.4)$ & $287(5.9)$ & $254(5.2)$ \\
\hline Myocardial infarction & $623(20.4)$ & $642(21.0)$ & $490(20.0)$ & $520(21.1)$ & $1,177(24.1)$ & $1,149(23.5)$ \\
\hline D-dimer $>2 \times$ ULN & $1,261(41.2)$ & $1,293(42.3)$ & $1,005(40.9)$ & $1,023(41.6)$ & $3,365(68.8)$ & $3,362(68.8)$ \\
\hline History of cancer & $548(17.9)$ & $525(17.2)$ & $269(11.0)$ & $248(10.1)$ & $387(7.9)$ & $428(8.8)$ \\
\hline History of VTE & $149(4.9)$ & $126(4.1)$ & $124(5.0)$ & $102(4.1)$ & $665(13.6)$ & $658(13.5)$ \\
\hline
\end{tabular}

Abbreviations: COPD, chronic obstructive pulmonary disease; $\mathrm{CrCl}$, creatinine clearance; SD, standard deviation; ULN, upper limit of normal; VTE, venous thromboembolism.

panel), whereas in patients with normal renal function in the MARINER study, the incidences of symptomatic VTE and VTE-related death were 0.65 and $0.98 \%$ with rivaroxaban (10 mg once daily) and placebo, respectively (- Fig. 1B, right panel). Taken together, these data suggest that the $10 \mathrm{mg}$ once daily dose of rivaroxaban reduces the risk of VTE in patients with impaired renal function to a similar extent as it does in patients with normal renal function, whereas the $7.5 \mathrm{mg}$ once daily dose of rivaroxaban is ineffective in patients with renal impairment.

\section{Safety}

In MAGELLAN overall, the incidence of major bleeding with rivaroxaban and enoxaparin/placebo up to day 35 were 1.08 and $0.38 \%$, respectively. The incidence of major bleeding (-Fig. 2A) in patients with renal impairment was higher than that in those with normal renal function in the rivaroxaban group ( 1.54 and $0.98 \%$, respectively), but not in the enoxaparin/placebo group ( 0.37 and $0.39 \%$, respectively). The incidence of major bleeding was lower in the MAGELLAN subpopulation than in the overall MAGELLAN population regardless of renal function. Within the subpopulation treated with rivaroxaban, the incidence of major bleeding was $0.94 \%$ in patients with renal impairment and $0.61 \%$ in those with normal renal function. In the enoxaparin/placebo arm, the incidence of major bleeding in patients with renal impairment was similar to that in patients with normal renal function ( 0.45 and $0.49 \%$, respectively). The incidence of clinically relevant bleeding with rivaroxaban and enoxaparin/placebo in the MAGELLAN subpopulation was similar to that in the overall MAGELLAN. However, the incidence of clinically relevant bleeding in the MAGELLAN subpopulation was still higher with rivaroxaban than with enoxaparin/ placebo $(4.71 \%$ vs. $2.12 \%$ in patients with renal impairment and $3.14 \%$ vs. $1.38 \%$ in patients with normal renal function) (-Fig. 2B).

In MARINER, which prospectively applied five exclusion criteria that were retrospectively used to create the MAGELLAN subpopulation, the overall incidence of major bleeding with rivaroxaban was lower than that in MAGELLAN overall (0.28 and $1.1 \%$, respectively). When these criteria were applied to create the MAGELLAN subpopulation, the incidence of major bleeding decreased from 1.1 to $0.61 \%$ in those with normal renal function and to $0.94 \%$ in those with impaired renal function ( - Fig. 2A). The incidence of bleeding with rivaroxaban $7.5 \mathrm{mg}$, which was administered to patients with renal impairment, was similar to that with the $10 \mathrm{mg}$ dose (0.37 and $0.27 \%$, respectively) (-Fig. 2A). Therefore, applying the criteria used in MARINER to exclude patients at high risk of bleeding appears to reduce the potential bleeding liability with the $10 \mathrm{mg}$ dose of rivaroxaban in patients with normal and impaired renal function.

\section{Rivaroxaban Exposures}

In the MARINER trial, the plasma concentration of rivaroxaban was measured in 72 and 245 patients in the $7.5 \mathrm{mg}$ and $10 \mathrm{mg}$ dose groups, respectively. Dose reduction from $10 \mathrm{mg}$ to $7.5 \mathrm{mg}$ in patients with renal impairment resulted in rivaroxaban plasma concentrations largely overlapping with those found with the $10 \mathrm{mg}$ dose in patients with normal renal function. - Fig. 3 shows the geometric means and 95\% CI for the plasma rivaroxaban concentration time curves for days 7 

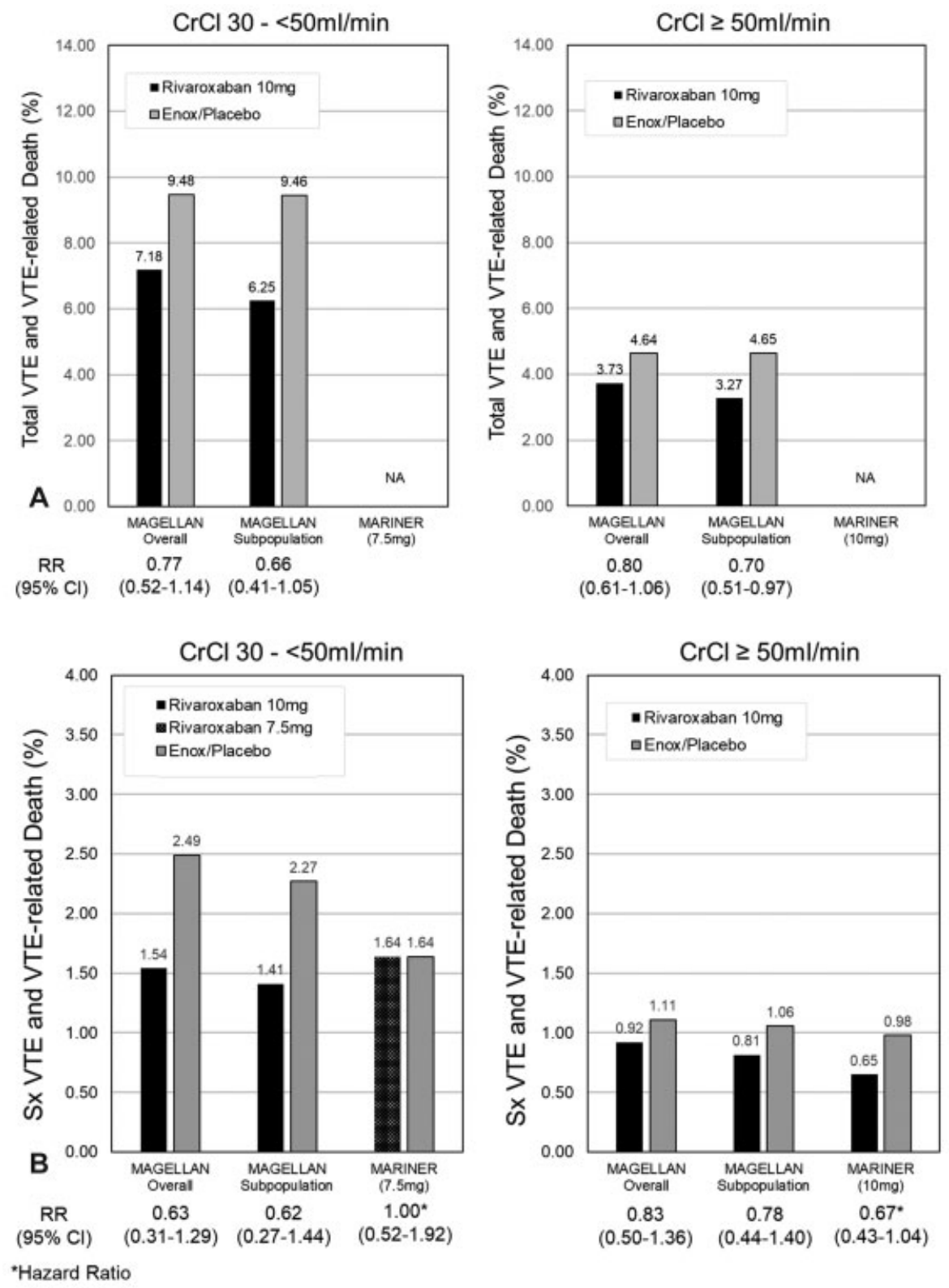

Fig. 1 (A, B) Key efficacy outcomes by renal function. (A) Total venous thromboembolism (VTE) (asymptomatic proximal deep vein thrombosis [DVT] and symptomatic VTE) and VTE-related death (\%).(B) Symptomatic VTE and VTE-related death (\%).

and 21 with the $7.5 \mathrm{mg}$ dose as a percentage of those found with the $10 \mathrm{mg}$ dose. - Table 2 shows the steady-state rivaroxaban exposures in patients with or without renal impairment in the MARINER and MAGELLAN trials. In MAGELLAN, the geometric mean of AUCss with the $10 \mathrm{mg}$ dose of rivaroxaban was $12.2 \%$ higher in patients with renal impairment than in those with normal renal function (2108.1 and1878.6 $\mu \mathrm{g}^{*} \mathrm{~h} / \mathrm{L}$, respectively). In MARINER, the geometric mean of AUCss for rivaroxaban was 9.4\% lower with the $7.5 \mathrm{mg}$ rivaroxaban dose in patients with renal impairment than with the $10 \mathrm{mg}$ rivaroxaban dose in patients with normal renal function (1903.8 and $2100.6 \mu \mathrm{g}^{*} \mathrm{~h} / \mathrm{L}$, respectively). Taken together with the safety and efficacy data, these findings suggest that although the $7.5 \mathrm{mg}$ dose in patients with renal impairment provides exposure similar to that in patients with normal renal function, it does not reduce the risk of VTE.
Therefore, rivaroxaban concentrations higher than those achieved with the $7.5 \mathrm{mg}$ dose are needed to maintain efficacy in patients with impaired renal function.

\section{Discussion}

The results of this study reveal that (1) acutely ill medical patients with renal impairment are at higher risk for VTE and bleeding than those with normal renal function, (2) compared with placebo, the use of a $7.5 \mathrm{mg}$ once daily dose of rivaroxaban in medically ill patients with renal impairment not only fails to reduce the risk of VTE, but increases the risk of bleeding to the same extent as the $10 \mathrm{mg}$ once daily dose of rivaroxaban in patients with normal renal function likely because the plasma rivaroxaban concentrations with the two doses are comparable, (3) a higher rivaroxaban exposure 

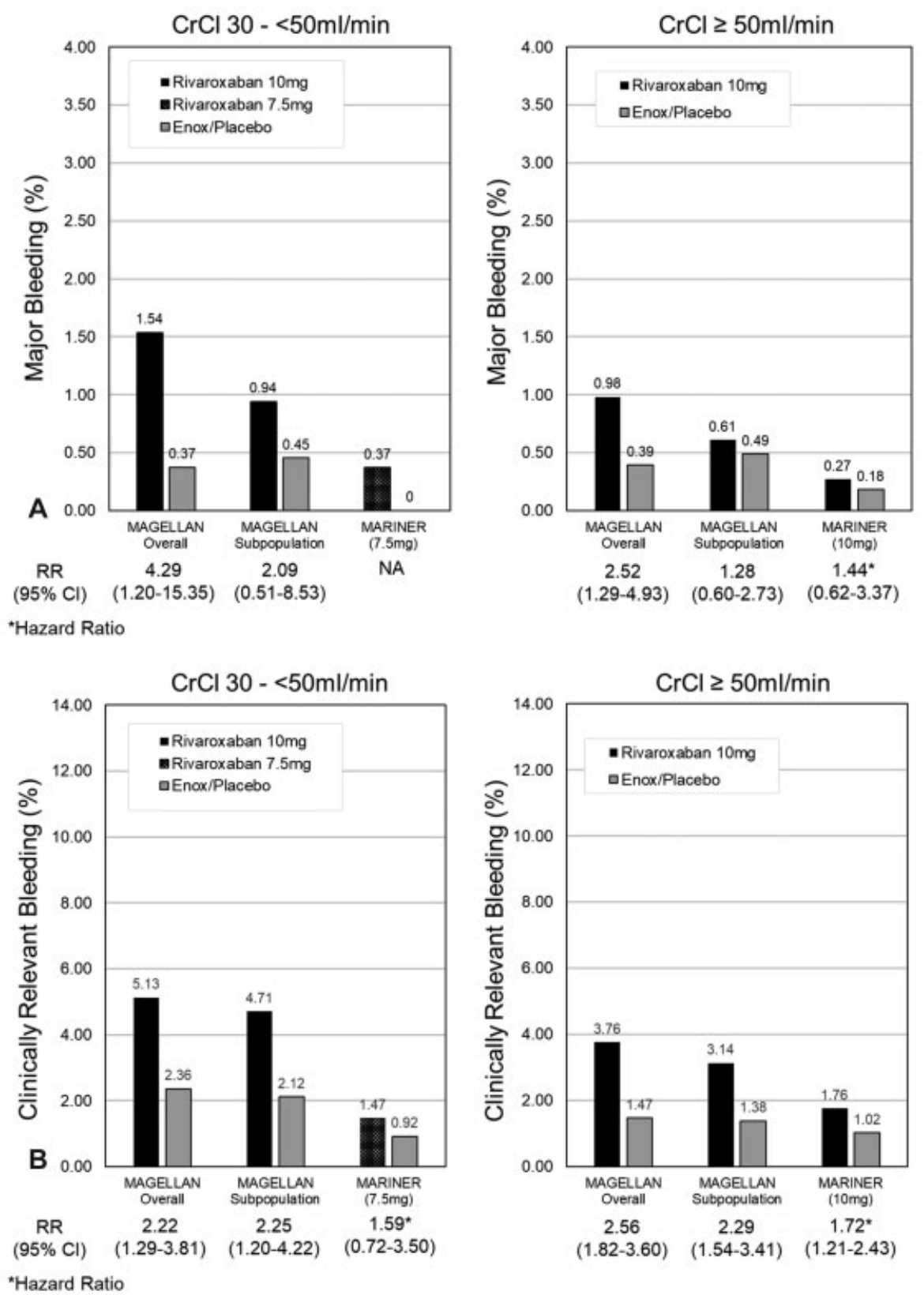

Fig. 2 (A, B) Key safety outcomes by renal function. (A) Major bleeding (\%).(B) Clinically relevant bleeding, the composite of major and clinically relevant nonmajor bleeding (\%).

than that obtained with the $7.5 \mathrm{mg}$ dose is needed to maintain efficacy in patients with impaired renal function, and (4) exclusion of patients at high risk for bleeding using clinical criteria alone appears to enhance the benefit-risk profile of the $10 \mathrm{mg}$ once daily regimen of rivaroxaban for extended thromboprophylaxis in acutely ill medical patients.

The observation that patients with renal impairment are at higher risk for VTE and bleeding than those with normal renal function is in line with previous findings. ${ }^{20,21}$ Because of the higher risk of bleeding, guidelines initially recommended either avoiding thromboprophylaxis with anticoagulants that bioaccumulate in such patients or considering a lower dose. ${ }^{5}$ Assessing the competing risks of VTE and bleeding in patients with renal impairment is complicated because they tend to be older and have more comorbid conditions than patients with normal renal function. ${ }^{18}$ Therefore, there remains a need for anticoagulant regimens that optimize benefit and risk in medically ill patients with impaired renal function who require thromboprophylaxis.

The five criteria used prospectively in the MARINER trial to exclude patients at risk for bleeding were identified by post hoc analysis of factors associated with major bleeding in the MAGELLAN study. With application of these exclusion criteria, the incidence of major bleeding with rivaroxaban in the MARINER trial was less than $0.4 \%$ in patients with or without renal impairment. However, at least two other factors may have contributed to the low incidence of major bleeding in the MARINER trial. First, patients were enrolled at the time of hospital discharge, thereby excluding those who bled while in hospital. Second, the dose of rivaroxaban 
Geometric Mean:

$\begin{array}{llll}(\% \text { of } 10 \mathrm{mg}) & 85 \% & 88 \% & 94 \%\end{array}$

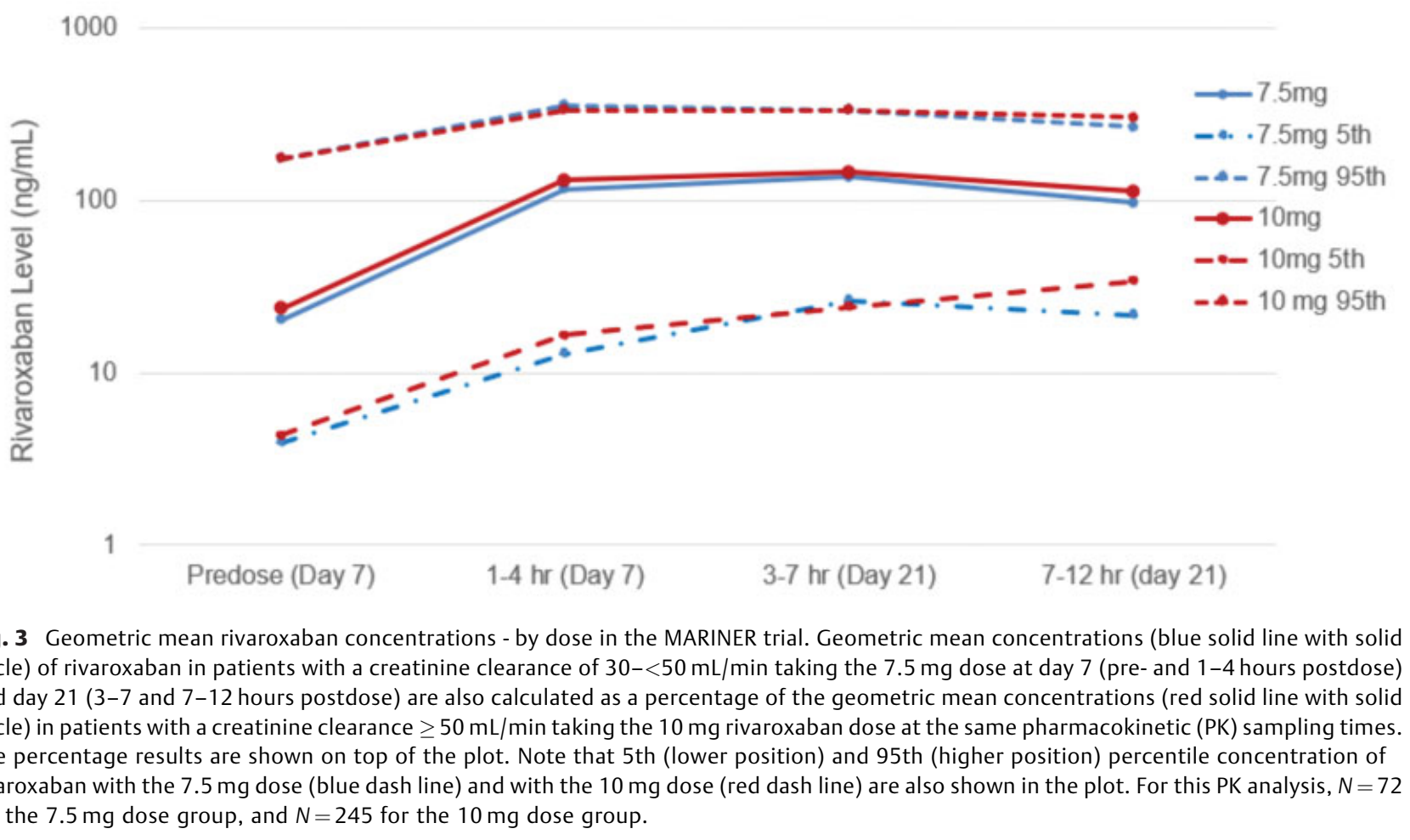

was decreased from 10 to $7.5 \mathrm{mg}$ in patients with a creatinine clearance less than $50 \mathrm{~mL} / \mathrm{min}$ to prevent increased drug exposure. Although this dose reduction strategy reduced the exposure, the $7.5 \mathrm{mg}$ rivaroxaban dose regimen was ineffective because the incidence of symptomatic VTE and VTErelated death with this regimen was nearly identical to that with placebo. The incidence of major bleeding with the $7.5 \mathrm{mg}$ dose of rivaroxaban in patients with renal impairment was higher than that with the $10 \mathrm{mg}$ dose of rivaroxaban in patients with normal renal function $(0.37$ and $0.27 \%$, respectively). Therefore, the low incidence of major bleeding with rivaroxaban observed in the MARINER trial is more likely to reflect the exclusion of patients at high risk for bleeding using clinical criteria than the dose reduc- tion strategy used in patients with impaired renal function or the delay in initiation of rivaroxaban until hospital discharge.

A failure of a dose reduction strategy to maintain efficacy in renally impaired patients was seen in the APEX trial with betrixaban. ${ }^{22}$ Taken together with the data from this analysis, these findings suggest that dose reduction in medically ill patients with renal impairment is problematic. Therefore, the $10 \mathrm{mg}$ dose of rivaroxaban should be used for thromboprophylaxis in such patients regardless of renal function just like the $20 \mathrm{mg}$ dose of rivaroxaban is used for VTE treatment in patients with normal or impaired renal function.

The importance of excluding patients at high risk for bleeding is highlighted by comparison of the results in the subpopulation of patients in the MAGELLAN trial with those

Table 2 Rivaroxaban exposure in MAGELLAN and MARINER by renal function

\begin{tabular}{|l|l|l|l|l|l|}
\hline Study & $\begin{array}{l}\text { Rivaroxaban dose }(\mathrm{mg}) \\
\text { (no. of subjects) }\end{array}$ & $\begin{array}{l}\mathrm{CrCl} \\
(\mathrm{mL} / \mathrm{min})\end{array}$ & $\begin{array}{l}\text { AUCss }(\mu \mathrm{g} \cdot \mathrm{h} / \mathrm{L}) \\
\text { Geometric mean } \\
(5-95 \% \text { percentile) }\end{array}$ & $\begin{array}{l}\text { Cmaxss }(\mu \mathrm{g} / \mathrm{L}) \\
\text { Geometric mean } \\
(5-95 \% \text { percentile) }\end{array}$ & $\begin{array}{l}\text { Cminss }(\mu \mathrm{g} / \mathrm{L}) \\
\text { Geometric mean } \\
(5-95 \% \text { percentile) }\end{array}$ \\
\hline \multirow{3}{*}{ MAGELLAN } & $\begin{array}{l}10 \mathrm{OD} \\
(6)\end{array}$ & $\geq 30$ to $<50$ & $\begin{array}{l}2108.1 \\
(1082.1-3467.6)\end{array}$ & $\begin{array}{l}185.6 \\
(128.4-268.6)\end{array}$ & $\begin{array}{l}20.5 \\
(6.88-84.0)\end{array}$ \\
\cline { 2 - 7 } & $\begin{array}{l}10 \mathrm{OD} \\
(32)\end{array}$ & $\geq 50$ & $\begin{array}{l}1878.6 \\
(1054.1-3443.0)\end{array}$ & $\begin{array}{l}186.5 \\
(127.5-311.6)\end{array}$ & $\begin{array}{l}13.19 \\
(2.73-66.8)\end{array}$ \\
\hline \multirow{2}{*}{ MARINER } & $\begin{array}{l}7.5 \mathrm{OD} \\
(72)\end{array}$ & $\geq 30$ to $<50$ & $\begin{array}{l}1903.8 \\
(1063.7-4072.5)\end{array}$ & $\begin{array}{l}162.5 \\
(113.5-248.9)\end{array}$ & $\begin{array}{l}21.1 \\
(4.1-111.3)\end{array}$ \\
\cline { 2 - 6 } & $10 \mathrm{OD}$ & $\geq 50$ & $\begin{array}{l}2100.6 \\
(1191.5-4075.1)\end{array}$ & $\begin{array}{l}185.1 \\
(135.4-258.3)\end{array}$ & $\begin{array}{l}21.4 \\
(4.8-106.0)\end{array}$ \\
\hline
\end{tabular}

Abbreviations: AUCss, area under the concentration curve over the dose interval at steady state; Cmaxss, maximum concentration at steady state; Cminss, minimum concentration at steady state; $\mathrm{CrCl}$, creatinine clearance; OD, once-daily dose. 
in the overall MAGELLAN population. Exclusion of patients with the five risk factors for bleeding in the MAGELLAN subpopulation was associated with a reduction in the incidence of major bleeding from 1.54 to $0.94 \%$ in patients with impaired renal function and from 0.98 to $0.61 \%$ in those with normal renal function. The comparison of the MAGELLAN, MAGELLAN subpopulation, and MARINER findings suggests that using the five criteria to exclude patients at high risk for bleeding will enhance the safety of the $10 \mathrm{mg}$ dose of rivaroxaban in patients with or without renal impairment.

This study has strengths and limitations. The strengths include the large sample size, the double-blind design of the trials, and the central adjudication of outcome events by committees whose members were unaware of treatment allocation. Limitations include the retrospective application of exclusion criteria used in MARINER to create the MAGELLAN subpopulation. Although the risk factors for bleeding were applied retrospectively, this excluded only about $20 \%$ of the patients enrolled in MAGELLAN. Furthermore, the outcomes used in the analyses were the same as those used in the trials to limit bias. The APEX study with betrixaban utilized a similar set of exclusion criteria which also improved the benefit-risk profile in medically ill patients. ${ }^{22}$

In summary, the results of this analysis suggest a favorable benefit-risk profile of the $10 \mathrm{mg}$ once daily dose of rivaroxaban for extended thromboprophylaxis in acutely ill medical patients with impaired or normal renal function. The safety of this regimen can be enhanced without loss of efficacy by excluding patients with key risk factors for bleeding. Additional studies are needed to identify effective and safe methods of thromboprophylaxis for patients at high risk for bleeding.

\section{What is known about this topic?}

- Patients with renal impairment are at increased risk of thrombosis and bleeding.

- Acutely ill, medical patients are at increased risk for venous thromboembolism and this can be reduced with extended thromboprophylaxis.

\section{What does this paper add?}

- A dose of $10 \mathrm{mg}$ once daily of rivaroxaban provides the best benefit-risk profile for extended thromboprophylaxis in renally impaired patients.

- The safety of rivaroxaban in renally impaired medically ill patients can be improved by avoiding patients with five key risk factors for bleeding.

\section{Authors' Contributions}

All authors contributed equally to the manuscript: (1) conception and design of the work, analysis, and interpretation of the data; (2) drafting the work or revising it critically for important intellectual content including: Introduction, Methods, Results, and Discussion; (3) final approval of the version to be published; and (4) agree- ment to be accountable for all aspects of the work in ensuring that the questions related to the accuracy or integrity of any part.

\section{Funding}

Bayer U.S. LLC and Janssen Research \& Development LLC sponsored the MAGELLAN and MARINER trials and the analysis reported here.

\section{Conflict of Interest}

J.I.W.: Bayer, Boehringer Ingelheim, Bristol-Meyers Squibb, Daiichi Sankyo, Ionis, Janssen, Merck, Novartis, Pfizer, Portola; A.C.S.: Janssen Research \& Development LLC, Bayer, Portola, Boehringer Ingelheim, ATLAS group: Research Grants and Consulting; C.L., J.X., W.L., E.S., J.A., D. A., E.S.B.: Janssen Research \& Development LLC: Employee/Stock; Y.D.S., T.E.S.: Bayer U.S. LLC: Employee; G.E.R.: Janssen Research \& Development LLC \& Bayer U.S. LLC, Daiichi Sankyo, Portola, Boehringer Ingelheim, PHRI Mc Master, Tetherex, Eli Lilly: Research Grants and Consulting.

\section{Acknowledgment}

The authors would like to thank the patients who participated in the MAGELLAN and MARINER trials.

\section{References}

1 Tadlock MD, Chouliaras K, Kennedy M, et al. The origin of fatal pulmonary emboli: a postmortem analysis of 500 deaths from pulmonary embolism in trauma, surgical, and medical patients. Am J Surg 2015;209(06):959-968

2 Spyropoulos AC, Anderson FA Jr, FitzGerald G, et al; IMPROVE Investigators. Predictive and associative models to identify hospitalized medical patients at risk for VTE. Chest 2011;140(03): 706-714

3 Hull RD, Merali T, Mills A, Stevenson AL, Liang J. Venous thromboembolism in elderly high-risk medical patients: time course of events and influence of risk factors. Clin Appl Thromb Hemost 2013;19(04):357-362

4 Cohen AT, Alikhan R, Arcelus JI, et al. Assessment of venous thromboembolism risk and the benefits of thromboprophylaxis in medical patients. Thromb Haemost 2005;94(04):750-759

5 Geerts WH, Bergqvist D, Pineo GF, et al. Prevention of venous thromboembolism: American College of Chest Physicians Evidence-Based Clinical Practice Guidelines (8th Edition). Chest 2008;133(6, Suppl):381S-453S

6 Jalal DI, Chonchol M, Targher G. Disorders of hemostasis associated with chronic kidney disease. Semin Thromb Hemost 2010;36 (01):34-40

7 Ribic C, Crowther M. Thrombosis and anticoagulation in the setting of renal or liver disease. Hematology (Am Soc Hematol Educ Program) 2016;2016(01):188-195

8 Cohen AT, Spiro TE, Bü ller HR, et al; MAGELLAN Investigators. Rivaroxaban for thromboprophylaxis in acutely ill medical patients. N Engl J Med 2013;368(06):513-523

9 Spyropoulos AC, Ageno W, Albers GW, et al; MARINER Investigators. Rivaroxaban for thromboprophylaxis after hospitalization for medical illness. N Engl J Med 2018;379(12):1118-1127

10 Cohen AT, Spiro TE, Büller HR, et al. Extended-duration rivaroxaban thromboprophylaxis in acutely ill medical patients: MAGELLAN study protocol. J Thromb Thrombolysis 2011;31 (04):407-416 
11 Raskob GE, Spyropoulos AC, Zrubek J, et al. The MARINER trial of rivaroxaban after hospital discharge for medical patients at high risk of VTE. Design, rationale, and clinical implications. Thromb Haemost 2016;115(06):1240-1248

12 Cockcroft DW, Gault MH. Prediction of creatinine clearance from serum creatinine. Nephron 1976;16(01):31-41

13 Spyropoulos AC, Lipardi C, Xu J, et al. Improved Benefit Risk Profile of Rivaroxaban in a Subpopulation of the MAGELLAN Study. Clin Appl Thromb Hemost 2019;25:1076029619886022

14 Mehran R, Rao SV, Bhatt DL, et al. Standardized bleeding definitions for cardiovascular clinical trials: a consensus report from the Bleeding Academic Research Consortium. Circulation 2011; 123(23):2736-2747

15 Mueck W, Lensing AW, Agnelli G, Decousus H, Prandoni P, Misselwitz F. Rivaroxaban: population pharmacokinetic analyses in patients treated for acute deep-vein thrombosis and exposure simulations in patients with atrial fibrillation treated for stroke prevention. Clin Pharmacokinet 2011;50(10):675686

16 Eriksson BI, Borris L, Dahl OE, et al; ODIXa-HIP Study Investigators. Oral, direct factor Xa inhibition with BAY 59-7939 for the prevention of venous thromboembolism after total hip replacement. J Thromb Haemost 2006;4(01):121-128

17 Eriksson BI, Borris LC, Dahl OE, et al; ODIXa-HIP Study Investigators. A once-daily, oral, direct factor Xa inhibitor, rivaroxaban (BAY 59-7939), for thromboprophylaxis after total hip replacement. Circulation 2006;114(22):2374-2381

18 Mantel N, Haenszel W. Statistical aspects of the analysis of data from retrospective studies of disease. J Natl Cancer Inst 1959;22 (04):719-748

19 Cox DR. Regression models and life-tables. J R Stat Soc B 1972;34 (02):187-220

20 Wattanakit K, Cushman M, Stehman-Breen C, Heckbert SR, Folsom AR. Chronic kidney disease increases risk for venous thromboembolism. J Am Soc Nephrol 2008;19(01):135-140

21 Trujillo-Santos J, Schellong S, Falga C, et al; RIETE Investigators. Low-molecular-weight or unfractionated heparin in venous thromboembolism: the influence of renal function. Am J Med 2013;126(05):425-434.e1

22 Cohen AT, Harrington RA, Goldhaber SZ, et al; APEX Investigators. Extended thromboprophylaxis with betrixaban in acutely ill medical patients. N Engl J Med 2016;375(06):534-544 